Journal of Mathematics and Statistics Studies

ISSN: $2709-4200$

DOI: $10.32996 / j m s s$

Journal Homepage: www.al-kindipublisher.com/index.php/jmss

\title{
Modeling the British Pound Sterling to Nigerian Naira Exchange Rate During the Covid-19 Pandemic
}

\author{
Ugochinyere Ihuoma Nwosu ${ }^{1}$, Chukwudi Paul Obite ${ }^{2} \square$ Prince Henry Osuagwu $^{3}$ and Obioma Gertrude \\ Onukwube $^{4}$ \\ ${ }^{1234}$ Department of Statistics, Federal University of Technology Owerri, Nigeria \\ $\square$ Corresponding Author: Chukwudi Paul Obite, E-mail: chukwudi.obite@futo.edu.ng
}

\section{ARTICLE INFORMATION ABSTRACT}

Received: 08 September 2021

Accepted: 05 October 2021

Published: 19 October 2021

DOI: 10.32996/jmss.2021.2.2.4

\section{KEYWORDS}

ARIMA, Artificial Neural Network, British Pound Sterling, Exchange Rate, Nigerian Naira, Random

Forest.
The British Pound Sterling (GBP) to Nigerian Naira (NGN) exchange rate has been grossly affected by the Coronavirus 2019 (Covid-19) pandemic. It has become pertinent to identify robust models that will help to cope with the variability associated with the pandemic. Many original studies found the ARIMA method to be highly useful in modeling and forecasting exchange rates. However, not much work has been done on modeling the GBP and NGN exchange rate during the covid-19 pandemic using machine learning models. This study focuses on modeling the exchange rate between the GPB and NGN during the period of the Covid-19 pandemic by adopting the process of model comparison using the Artificial Neural Network (ANN), Autoregressive Integrated Moving Average (ARIMA), and Random Forest models to obtain an optimal model and forecasts from the model. Secondary data of the GBP to NGN exchange rate within the period of the Covid-19 pandemic from exchangerate.org.uk were used. The two machine learning models (ANN and random forest) performed better than the ARIMA model. The RF, though performed well in the training set, was outperformed in the test set by the ANN model. The ANN model was chosen to model and forecast the GBP and NGN exchange rate during the Covid-19 pandemic. The predicted fall in the GBP to NGN exchange rate to 570 by December 2021 and 575 by September 2022 using the ANN model will have a huge effect on the economy of the country as the country depends largely on imported goods. The Government and policymakers must put in place structural measures that will avoid the looming crisis.

\section{Introduction}

Over the years, the foreign currency exchange rate has portrayed the ratio at which one currency is exchanged with another currency. It is a metric for an economy's domestic wealth. These rates give the required data for currency trading in the international monetary market systems. One of the endogenous elements that might affect the economy is exchange rate policy (Jameela, 2010). One of the most crucial indicators of a country's economic health, alongside interest rates and inflation, is its currency exchange rate. Exchange rates play a key role in setting a nation's rate of trade, which is critical in practically every free market economy on the planet. They are one of the most closely watched, scrutinized, and governmentally controlled economic indicators. For most affluent countries, an accurate exchange rate is important for economic progress, however, significant volatility has been a serious concern for the economies of a number of African countries, including Nigeria. The country has transitioned from a pegged or inflexible exchange rate regime to a more flexible regime since the introduction of the structural adjustment program policy in 1986. "Negative real interest rates are usually not a problem on their own" Hanson and Craig (1985) write, "but a sign of far greater difficulties in which the entire macroeconomic framework is out of line."

Coronavirus disease 2019 (Covid-19) was first discovered in Wuhan, China, in December 29, 2019 (Nwosu and Obite, 2021). Since then, the virus has spread quickly and globally, with Thailand becoming the first country outside of China to report a Covid-19

Copyright: (C) 2021 the Author(s). This article is an open access article distributed under the terms and conditions of the Creative Commons Attribution (CC-BY) 4.0 license (https://creativecommons.org/licenses/by/4.0/). Published by Al-Kindi Centre for Research and Development, London, United Kingdom. 
case on January 13, 2020. (World Health Organization, 2020). As of June 11, 2020, 11:58 GMT, there were 7,484,084 confirmed cases and 419,518 deaths globally (World meter) and 13,873 confirmed cases with 382 deaths in Nigeria (NCDC) from the Covid19 pandemic.

Following the 2016 recession in Nigeria, it was nearly universally assumed that the sudden and protracted drop in oil prices was the primary reason for the country's downturn. However, no one predicted that a public health crisis in 2020 would lead to a countrywide economic downturn (Ozili, 2020). It is exactly the same for the exchange rate, which was previously assumed to be only influenced by fluctuations in oil prices without considering the effect of a pandemic. The rapid spread of COVID-19 has had and continues to have an impact on the global economy in general and the NGN rate in particular. In the face of the pandemic, all of the key drivers of the exchange rate, such as oil prices, non-oil exports, and diaspora remittances, appear to be steadily declining. The outbreak of the Covid-19 pandemic in the world is having enormous negative effects on emerging markets and the Nigerian economy is no exception. Nigerian economic growth has always depended on crude oil export amongst others while most sectors of the economy depend on imports. The outbreak has effects on the exchange rates because with a sharp drop in oil prices, border closures, non-existent buffer, depletions in Nigeria's excess crude account; financial conditions have become a fight and the exchange rates are under excess pressure.

The impact of the Covid-19 shocks is exacerbated by the existence of these underlying economic conditions, which are causing liquidity problems in the foreign exchange (FOREX) market. As a result of exchange rate depreciation, costs are rising, foreign credit lines are being canceled, industrial capacity utilization is falling, and purchasing power and job opportunities are dwindling. Forecasting currency rates is a difficult task. Many economic factors influence exchange rates, including oil prices, export revenues, and, most recently, the Covid-19 outbreak. Conventional time series methods do not perform well on economic data, as the exchange rate has a trend cycle and irregularities, according to Yao (2000). As a result, using machine learning algorithms to forecast exchange rates is being studied. Nigeria is well-known for being heavily reliant on imports, necessitating large sums of foreign exchange profits to fund these imports and keep the value of its currency stable. Unfortunately, the vast bulk of Nigeria's imports are for consumption, leaving very little for production and almost none for foreign exchange earning economic activities. The volatile and falling oil prices accompanied with corruption and little or no value substitute to oil earnings are proven pointers that the national economy takes a very bleak future. In the recent history of the country, the Covid-19 pandemic period has been one of the worst crises so far which is seen to be impending if no extreme workable measure is in sight and the naira is allowed to totally collapse. However, previous studies have considered different models with debatable outcomes.

Briefly, Weihang and Zhang (2011) used a random forest to predict the Chinese Yuan exchange rates. They reported that the random forest algorithm outperformed the Support Vector Machine (SVM) and linear regression methods. Zhang (2003) developed a hybrid ARIMA/ANN model to examine the US Dollar/ British Pound Sterling (USDGBP) rate, concluding that the hybrid model produces more reliable results than both the ARIMA and ANN models. Babu and Reddy (2015) used the conventional times series method (ARIMA) and nonlinear methods such as Neural Networks and Fuzzy Networks to study the predictability of Indian Rupee exchange rates versus USD, GBP, Euro, and Japanese Yen. They concluded that the ARIMA model outperforms the ANN and Fuzzy systems. Appiah and Adetunde (2011) used the ARIMA approach to estimate the monthly exchange rate between the Ghana Cedi and the US Dollar. The study found that the projected rates were in line with the observed series' declining tendency. The ARIMA $(1,1,1)$ model was found to be the most appropriate.

Etuk (2014) observed that the SARIMA model is better and able to capture the intrinsically seasonal nature of the series than the ARIMA model. They concluded that the daily NGN per British Pound Sterling exchange rates are seasonal of a one-week period and follow a $(0,1,1) *(0,1,1)$ SARIMA model. Etuk (1998) employed a seasonal ARIMA model to forecast NGN to USD. He indicates that between 2004 and 2007, the series (exchange rate) had a negative trend and was stable in 2008. The ARIMA technique was also employed by Onasanya et al. (2013) and Okon and Ikpang, (2020) to forecast the NGN to the USD exchange rate. The ARIMA $(1,2,1)$ and ARIMA $(2,1,3)$ models respectively were the best at explaining the data. There is an upward trend according to the findings from Onasanya et al. (2013). The out-of-sample forecast plot suggested that the Naira will continue to devalue against the dollar during the Covid-19 pandemic period, according to Okon and Ikpang (2020).

Finally, Udoye (2009) looked at the factors that influenced the real exchange rate in Nigeria in recent years, from 1970 to 2006. The author highlighted lags in the real exchange rate, inflation rate, real gross domestic product, real interest rate, and trade openness as potential determinants of real exchange rates. The findings imply that the one-year past value real exchange rate in Nigeria is a significant driver of the real exchange rate.

Many of the original researches reviewed above found the ARIMA method to be highly useful in modeling and forecasting exchange rates. However, not much work has been done on modeling the GBP and NGN exchange rate and the different exchange rates during the covid-19 pandemic using machine learning models. The use of machine learning methods to model the GBP to NGN exchange rate has been grossly understudied. Thus our motivation is to fill this research gap. The aim of this study is to 
model the exchange rate between the GPB and NGN during the period of the Covid-19 pandemic by adopting the process of model comparison using the ANN, ARIMA, and Random Forest models to obtain the optimal model and forecasts from the model. The specific objectives were to (i) estimate the parameters of the three models and (ii) identify the appropriate and efficient time series model for the exchange rate of the GPB to NGN by comparing the forecast and actual values during the period of the Covid19 pandemic. If the unstable exchange rate of GPB to NGN during the period of the Covid-19 pandemic can be accurately predicted, identified, and most importantly corrected; the economy of the country will take a rapid growth and also give the government a good policy decision making-base that will re-strategize the nations' financial market.

\section{Methods}

We used secondary data of the GBP to NGN exchange rate within the period of the Covid-19 pandemic effect - September $9^{\text {th }}$, 2020 to March $5^{\text {th }}, 2021$. The data were obtained from the exchange rate website (exchangerate.org.uk/GBP-NGN-exchange-ratehistory.html). The data were split into two groups: training and testing. The training data were used to estimate the model's parameters, whereas the test data were used to validate the model and determine how well it performs on new data.

The methods applied to analyze the data and obtain useful results capable of showing the necessary information required for the study are the ANN, ARIMA, and RF models. All the models were fitted on the GBP to NGN data. The ARIMA model is a traditional statistical model, but the ANN and RF models are machine learning models. The RMSE, MAPE, and MDM tests were used to find the optimal model. In the machine learning models, the time variable and lags (Lag 1 and 5) of the exchange rate were employed as explanatory factors. The Lag 1 is the closest previous exchange rate value and Lag 5 is selected since the data are 5 -day weekly data; both of which will be quite valuable in understanding the current exchange rate values of the GBP to NGN during the Covid19 pandemic period.

\subsection{The ANN Model}

The input, hidden, and output layers make up the ANN. There are nodes in the various tiers. All of the input layers' nodes are networked to all of the hidden layer's nodes, and all of the hidden layer's nodes are networked to the node(s) in the output layer. Both the hidden and output layers have an activation function applied to them. Figure 1 shows the ANN model's design

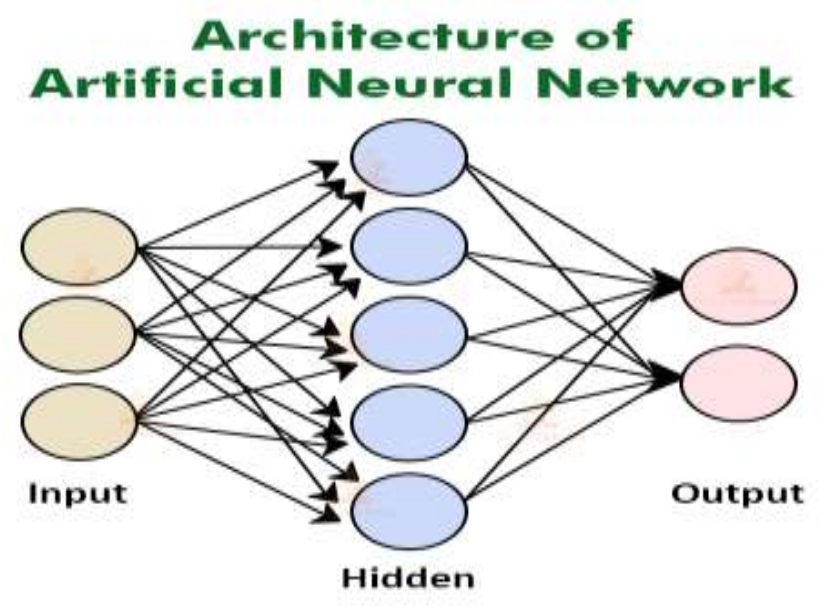

Figure 1: The ANN model's design.

Source: techvidvan.com

The equation of the ANN model is written as:

$$
\widehat{y}\left(x_{i}, w\right)=\Phi_{0}\left(\alpha+\sum_{h=1}^{H} w_{h} \Phi_{h}\left(\alpha_{h}+\sum_{j=1}^{J} w_{j h} x_{i j}\right)\right)
$$

where

$\hat{y}\left(x_{i}, w\right)$ is the estimated output,

$w_{j h}$ is the input to hidden nodes weight,

$w_{h}$ is the hidden to output node weight,

$x_{i j}$ is the input node, 
$\alpha$ and $\alpha_{h}$ are bias,

$\Phi_{0}$ and $\Phi_{h}$ are activation functions.

Transmission from the input layer to the hidden layer is done using the logistic activation function, whereas transmission from the hidden layer to the output layer is done using the linear activation function. Weights are assigned to the connections between nodes. The quadratic error function given in Equation (2) is minimized to estimate the weighs.

$$
E_{Q}=\sum_{i=1}^{n}\left(\hat{y}\left(x_{i}, w\right)-y_{i}\right)^{2}
$$

where

$y_{i}$ is the output.

The Olden approach was used to estimate the relevance of each of the input nodes (Bartholomew et al., 2021; Olden, 2004).

To speed up the convergence of the neural network, the input nodes were normalized using the min-max approach described in Equation (3) (Nwosu et al., 2021; Obite et al., 2020).

$$
y_{i}=\frac{x_{i}-x_{\min }}{x_{\max }-x_{\min }}
$$

where,

$y_{i}$ is the normalized value.

$x_{i}$ is the original value.

$x_{\text {min }}$ is the minimum value.

$x_{\max }$ is the maximum value.

\subsection{The ARIMA Model}

Box and Jenkins (1976) established the ARIMA model, which is a mixture of the Autoregressive (AR) and Moving Average (MA) models on stationary data.

The ARIMA $(p, d, q)$ model is given as:

$$
\eta(\theta)(1-\theta)^{d} X_{t}=\lambda(\theta) Z_{t}
$$

where

$\eta(\theta)$ is the $\mathrm{AR}(\mathrm{p})$ characteristic polynomial

$\lambda(\theta)$ is the $\mathrm{MA}(\mathrm{q})$ characteristic polynomial

$(1-\theta)^{d}$ is the differencing of order " $\mathrm{d}$ "

$X_{t}$ is the observed value at a time $t$

$Z_{t}$ is the random error

The value of " $\mathrm{d}$ " is the minimum times of differencing to make the data stationary. The Autocorrelation (ACF) and Partial Autocorrelation (PACF) plots are examined carefully. If there is a sharp drop into the significant limit in the PACF or ACF plots, the lag before the sharp drop is the order of " $p$ " and " $q$ " respectively. If the lags decay slowly in the PACF or ACF plots, the value for "p" or "q" respectively is zero.

Using the Akaike Information Criterion (AIC), the proposed model is compared to other ARIMA models in order to find a better model. The residuals are tested for white noise as explained in Obite et al. (2021). Only if the errors are white noise is the model adequate for the data.

\subsection{The RF Model}


Random forest (Breiman, 2001) is an ensemble learning technique that uses data attributes to generate several decision trees, which are then merged to improve prediction performance. The steps in the random forest are:

a. Sample $m$ cases from the training set with replacement at random from the original data with $\mathrm{n}$ cases and use them for growing the tree.

b. If there are $\mathbf{x}$ explanatory variables, a number $\mathbf{x} \leq \mathbf{X}$ is chosen and $\mathbf{x}$ variables are selected at random out of the $\mathbf{X}$ variables at each node. To split the node, we utilized the best split on the $x$ specified variables. In the process of developing the forest, the number $\mathrm{x}$ remains constant.

The forest error rate will increase if two trees are correlated. A prediction is produced by taking the average (for regression) or majority voting (for classification) of the predictions from all trees in the forest. A random forest model is explained graphically in Figure 2.

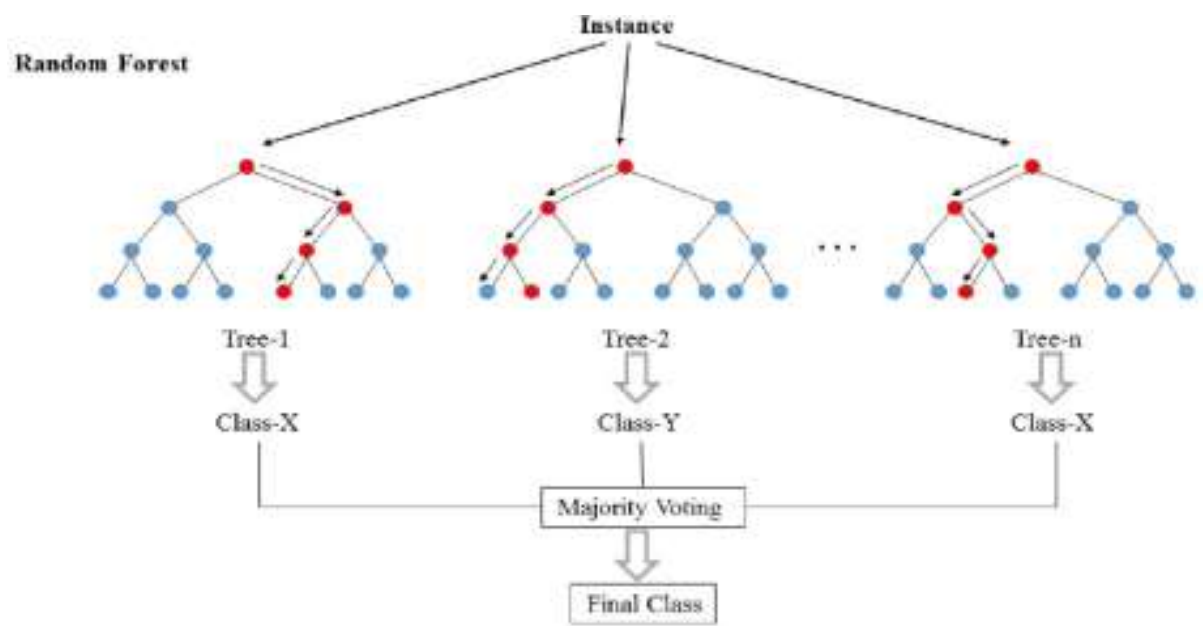

Figure 2: A Random forest.

Source: Analyticsvidhya.com

\subsection{Variable Importance}

The relevance of a variable relates to how much that variable is used by a model to produce correct predictions. The variable relevance was estimated using the increase in mean square error (IMSE) and the increase in node impurity (INP). When a less important variable is randomly permuted, it will have little effect on the IMSE and INP.

\subsection{Performance Measures}

The RMSE, MAPE, and MDM tests were utilized to choose the most suitable model for the exchange rate of GBP to NGN. The best model is the one with the lowest RMSE and MAPE values. The alternative hypothesis (model 2 fit the data better than model 1 ) was compared to the null hypothesis (model 1 is equal to model 2 ) at the 0.05 level of significance using the modified DieboldMariano test

\section{Results}

\subsection{The ARIMA model}

Figure 3 shows a linear upward trend as a result of the current effective rate of the global crisis (Covid-19 pandemic period) to the exchange rate, and this indicates that the training set is not stationary. This is also confirmed by the ADF test. We rejected the null hypothesis of stationarity of the data since the $p$-value of the ADF test of lag order $5(0.4134)$ is greater than the level of significance (0.05), and conclude that there is no stationarity in the exchange rates. The first order differencing suggests an order 1 for " $d$ " of the model. We proceeded to the first-order differencing to attain stationarity. 


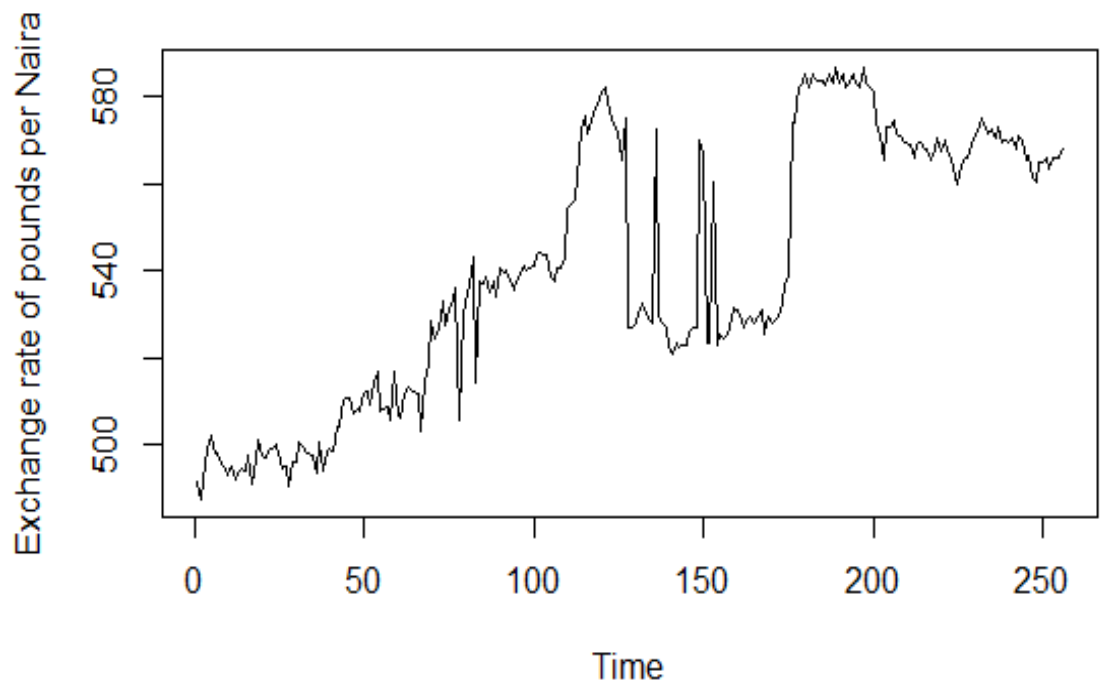

Figure 3: The GDP and NGN exchange rate data for the training set.

After the first order differencing, the series became stationary ( $p$-value of the ADF test of order $6(0.01)$ is less than the level of significance (0.05)). The ACF and PACF plots of the first order differencing series suggested an order 1 and 2 for MA and AR respectively.

The proposed ARIMA model is of order $(2,1,1)$. Model comparison was performed with results from $(2,1,4),(2,1,2),(2,1,3)$, and $(1,1,2)$ respectively in order to determine the model with the best and least AIC; and model $(1,1,2)$ outperformed all the different ARIMA models as it has the least AIC in Table 1.

Table 1: The different ARIMA Models

\begin{tabular}{ll}
\hline ARIMA Models & AIC \\
\hline $2,1,3$ & 1316.87 \\
$2,1,1$ & 1320.35 \\
$1,1,2$ & 1314.17 \\
$2,1,4$ & 1318.58 \\
$2,1,2$ & 1316.17 \\
\hline
\end{tabular}

The ARIMA $(1,1,2)$ model is given as:

$y_{t}=-0.871 y_{t-1}+\varepsilon_{t}+0.5687 \varepsilon_{t-1}-0.4313 \varepsilon_{t-2}$

The errors are white noise as a careful study of the residuals shows no trend in the residuals, they follow a normal distribution and all the lags in the ACF plots are within the significant limit. This was also confirmed by a non-significant Ljung-Box test ( $p$-value $0.2494>0.05)$.

\subsection{The ANN model}

We made an attempt of different node sizes ranging from 1-8 in the hidden layer of the ANN model to get the best fit for the exchange rate of GBP to NGN as shown in Table 2. The node size of five in the hidden layer is chosen for the ANN model as it has the least values of RMSE and MAPE, in the training set which we considered to be the best. The ANN is shown in Figure 3. The Lag 5 and time variables are evidently proven to have more effect on predicting the GBP to NGN exchange rate as shown in Figure 4. Hence, the exchange rate of the GBP to Nigeria Naira has been considered to be affected more by the rate of the same day in the previous week and time 
Table 2: The ANN models

\begin{tabular}{lllll}
\hline & Training Set & & Test Set & \\
Hidden Nodes & MAPE & RMSE & MAPE & RMSE \\
\hline 1 & 0.01073 & 9.92961 & 0.00595 & 4.55188 \\
2 & 0.01027 & 9.39313 & 0.02994 & 17.4794 \\
3 & 0.00988 & 9.23479 & 0.01307 & 8.00863 \\
4 & 0.01053 & 9.55347 & 0.01 & 6.45288 \\
5 & 0.01047 & 9.49559 & 0.00535 & 4.00709 \\
6 & 0.01009 & 9.16382 & 0.01818 & 10.8856 \\
7 & 0.01048 & 9.57746 & 0.00742 & 5.10053 \\
8 & 0.01056 & 9.60823 & 0.0066 & 4.65473 \\
\hline
\end{tabular}

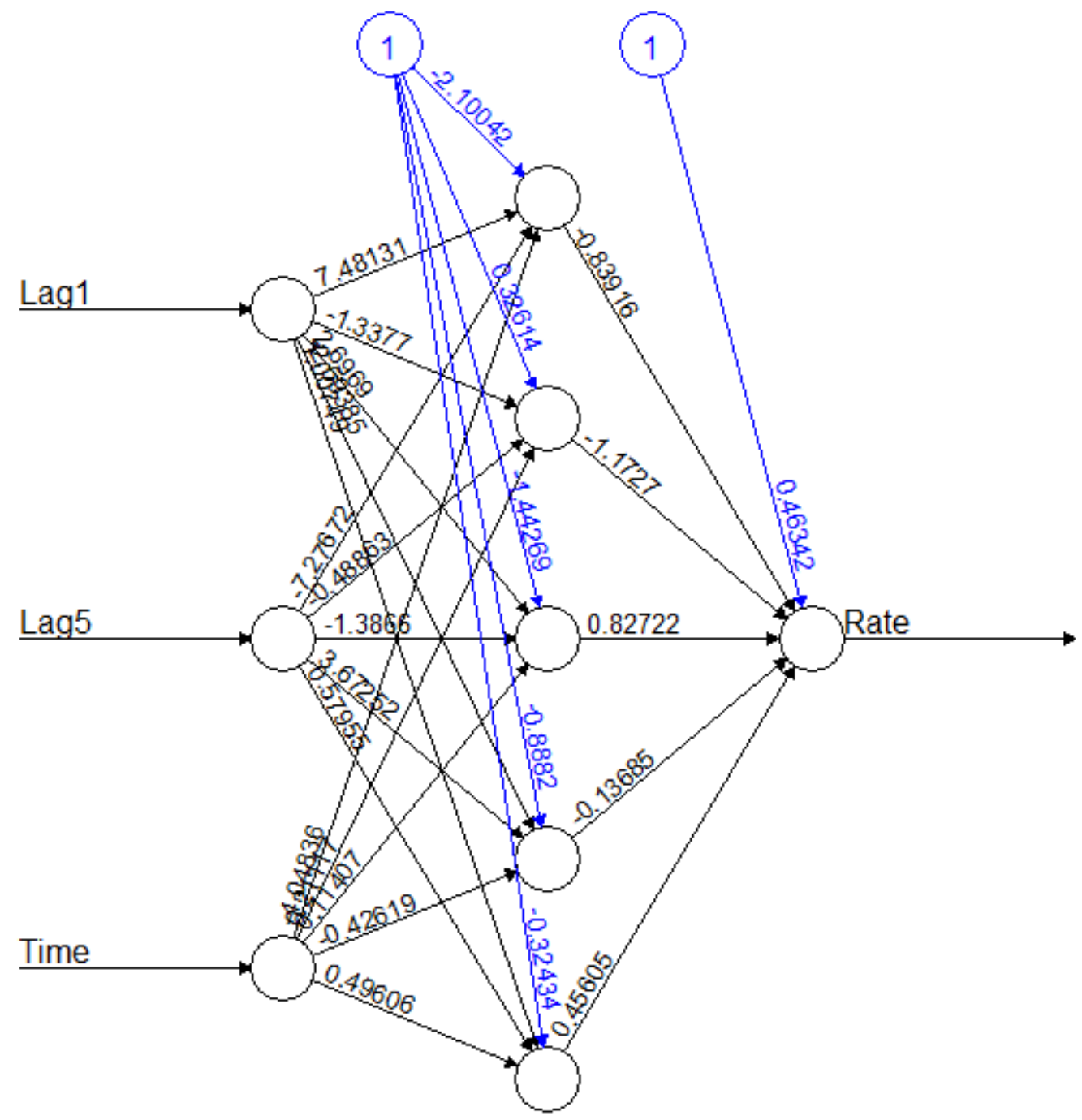

Error: 0.818853 Steps: 845

Figure 3: The $\operatorname{ANN}(3,5,1)$ model 


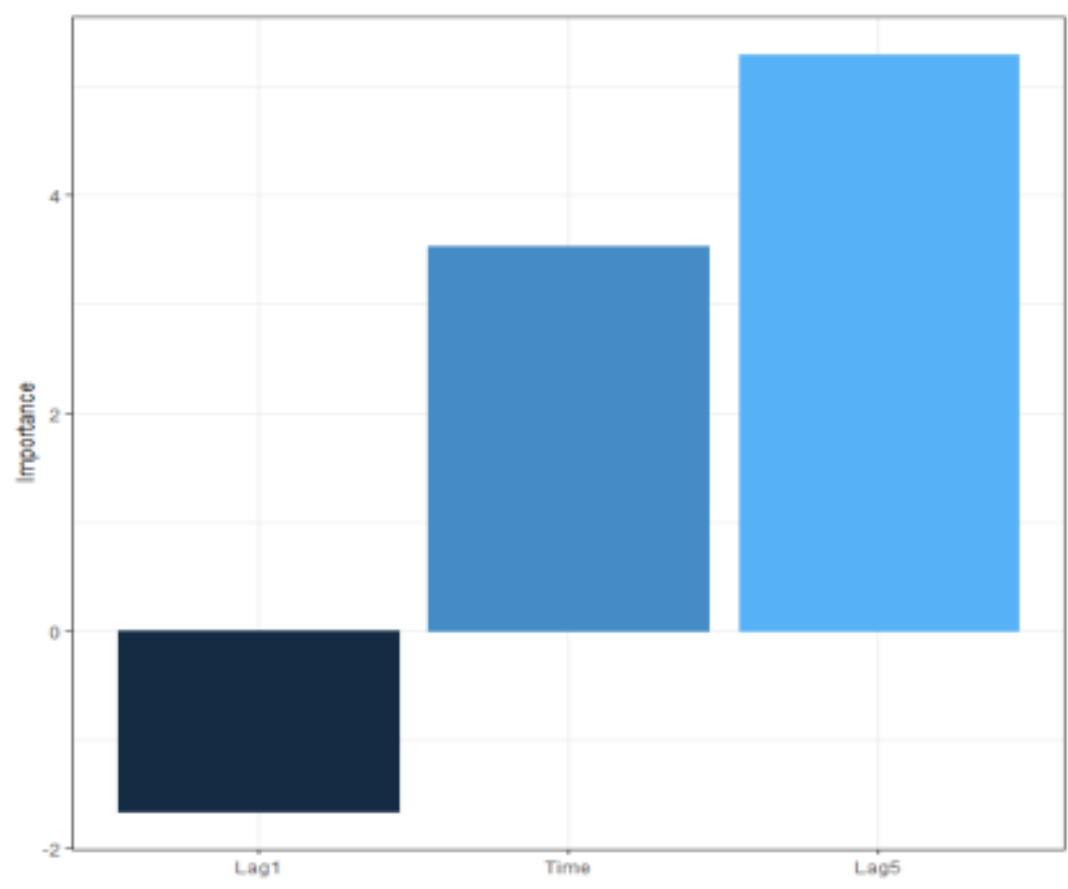

Figure 4: Importance of the variables

\subsection{The random forest model}

The random forest model was also fitted in the exchange rate series. The performance measures of the different choices of the variables selected are given in Table 3. Using only one of the explanatory variables to split the node gave the best results. The Lag 1 and Time variable has more contribution in estimating the GBP to NGN exchange rate. The IMSE and the INP increase the most when the "Lag1" and "Time" variables are randomly permuted, as shown in Table 4.

Table 3: The different performance in the RF model

\begin{tabular}{l|ll|ll}
\hline & Training Set & & Test Set & \\
No. of variables & MAPE & RMSE & MAPE & RMSE \\
\hline 1 & 0.0051 & 4.8046 & 0.0153 & 9.8802 \\
2 & 0.0049 & 4.7307 & 0.0017 & 10.8809 \\
3 & 0.0051 & 4.8645 & 0.0162 & 10.3891 \\
\hline
\end{tabular}

Table 4: The variable importance of model

\begin{tabular}{lll}
\hline & IMSE & INP \\
\hline Lag1 & 24.19 & 40022.98 \\
Lag5 & 22.1 & 29844.84 \\
Time & 23.84 & 33889.97 \\
\hline
\end{tabular}

\subsection{The ANN, ARIMA, and Random Forest Models}

The ARIMA $(1,1,2)$, ANN, and random forest models are compared in both the training and test sets using the RMSE, MAPE, and MDM performance measures to obtain a reliable model for studying and forecasting the exchange rate of GBP to NGN as shown in Table 5 and 6 . There may be a difference in the RMSE and MAPE values but the difference may be insignificant. The significance of the difference is tested using the MDM test. The ARIMA model performed poorly when compared to the ANN $(3,5,1)$ and random forest models. The random forest model had the best performance in the training test than both models but was outperformed by the ANN model in the test set. This means that the ANN model has higher accuracy in predicting a new dataset that was not used in training the model, and the ANN model is selected as the best model for the GBP to NGN exchange rate.

Table 5: The ANN, ARIMA, and random forest models 


\begin{tabular}{l|ll|ll}
\hline \multirow{3}{*}{ Models } & Training set & & Test set & \\
\cline { 2 - 5 } & RMSE & MAPE & RMSE & MAPE \\
\hline ARIMA & 9.3902 & 0.0106 & 10.6207 & 0.0167 \\
ANN & 9.4956 & 0.0105 & 4.0071 & 0.0054 \\
RF & 4.8046 & 0.0051 & 9.8802 & 0.0153 \\
\hline
\end{tabular}

Table 6: Modified Diebold-Mariano test for the different machine learning models

\begin{tabular}{|c|c|c|c|c|c|c|c|}
\hline & & \multicolumn{6}{|c|}{ First Model } \\
\hline & & $\begin{array}{l}\text { ARIMA } \\
\text { Training }\end{array}$ & Test & $\begin{array}{l}\text { ANN } \\
\text { Training }\end{array}$ & Test & $\begin{array}{l}\text { RF } \\
\text { Training }\end{array}$ & Test \\
\hline ARIMA & $\begin{array}{l}\text { MDM } \\
\text { P-value }\end{array}$ & & & $\begin{array}{l}0.326 \\
0.373\end{array}$ & $\begin{array}{l}-7.870 \\
1.000\end{array}$ & $\begin{array}{l}-4.196 \\
1.000\end{array}$ & $\begin{array}{l}-0.785 \\
0.783\end{array}$ \\
\hline ANN & $\begin{array}{l}\text { MDM } \\
\text { P-value }\end{array}$ & $\begin{array}{l}-0.325 \\
0.622\end{array}$ & $\begin{array}{l}7.870 \\
0.00 * *\end{array}$ & & & $\begin{array}{l}-4.209 \\
1.000\end{array}$ & $\begin{array}{l}9.480 \\
0.000 * *\end{array}$ \\
\hline RF & $\begin{array}{l}\text { MDM } \\
\text { P-value }\end{array}$ & $\begin{array}{l}4.196 \\
0.000^{* *}\end{array}$ & $\begin{array}{l}0.785 \\
0.218\end{array}$ & $\begin{array}{l}4.209 \\
0.000 * *\end{array}$ & $\begin{array}{l}-9.480 \\
1.000\end{array}$ & & \\
\hline
\end{tabular}

A plot of the true value (TV) and predicted values of the test set from the ANN, ARIMA, and random forest models are given in Figure 5. The plot shows how the ANN outperformed the ARIMA and random forest models in the test set with minimum errors. The forecasts from the ARIMA model were very far from the true values.

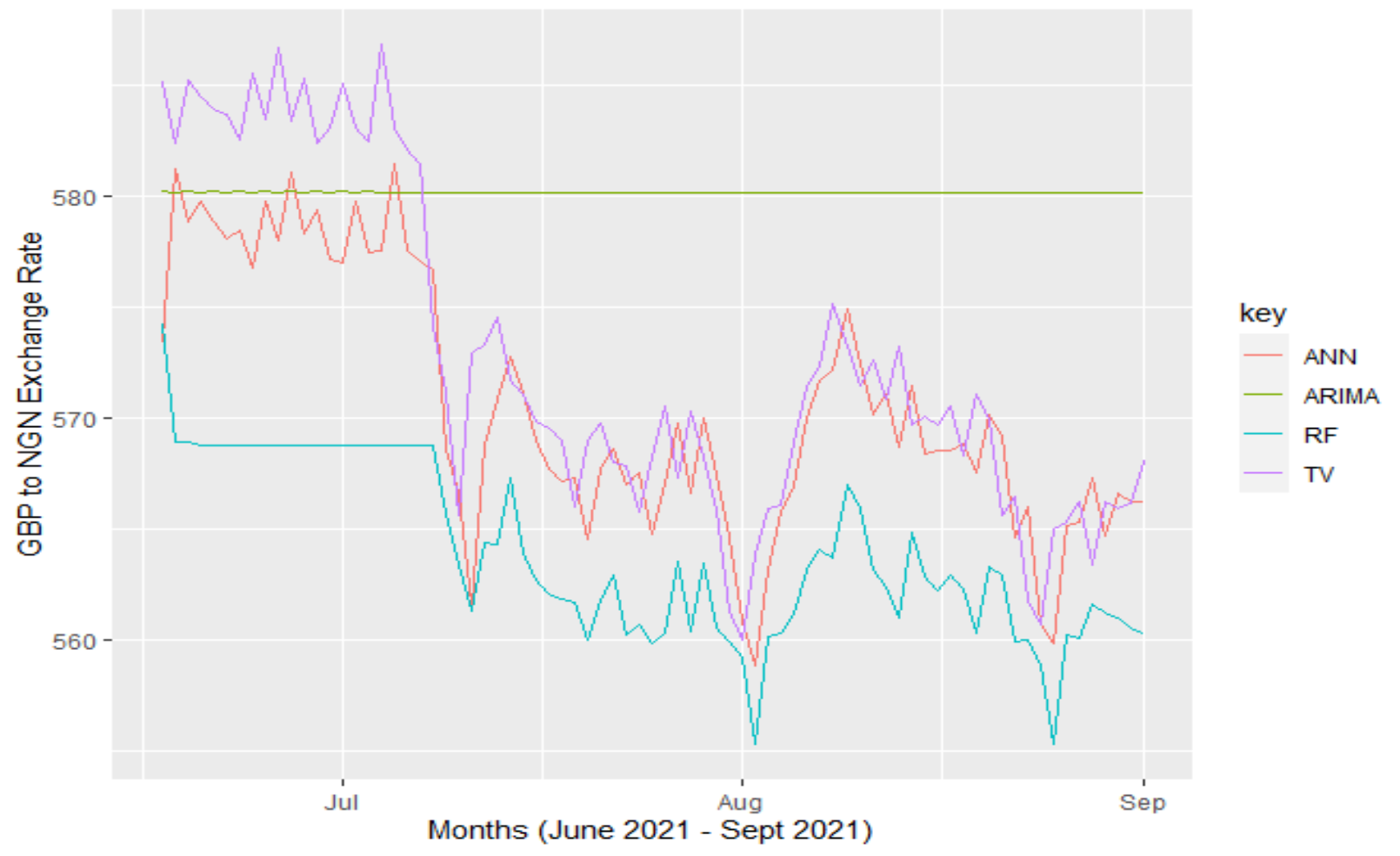

Figure 5: Plot of the forecasts from the ANN, ARIMA, and random forest models; and the True Value (TV) for the test set.

The GBP to NGN exchange rate is predicted to be about 570 by December 2021 and 575 by September 2022 using the ANN model. The NGN is predicted to depreciate further against the GBP.

\section{Discussion}


There was no seasonal component in the exchange rate of GBP to NGN during the Covid-19 pandemic and this is contrary to the result of Etuk (2014) that observed a seasonal one-week period. This could be a result of the pandemic. The ARIMA model was used in many original studies (Appiah and Adetunde, 2011; Etuk, 1998; Okon and Ikpang, 2020; Onasanya et al. 2013) to model other currencies against the NGN did not perform very well in this study. The machine learning models were better fit to the GBP to NGN exchange rate than the ARIMA model and this is in agreement with Nwosu et al. (2021) and Obite et al. (2021). The past exchange rate is a significant driver of the exchange rate and this agrees with Udoye (2009) though, in this present study, it was the five-day past exchange rate and not the one-year past exchange rate that significantly contributed to the current exchange rate.

\section{Conclusion}

In this study, we determined the optimal model to model the complex structure of the GBP and NGN exchange rate during the pandemic period. Many original studies found the ARIMA method to be highly useful in modeling and forecasting exchange rates. However, not much work has been done on modeling the GBP and NGN exchange rate and the different exchange rates during the covid-19 pandemic using machine learning models; and this motivated this study to fill the research gap. The ANN, ARIMA, and random forest models were fitted on the GBP to NGN exchange rate and the results were compared using the RMSE, MAPE, and Modified Diebold Mariano (MDM) tests. The two machine learning models (ANN and random forests) performed better than the ARIMA model. Though the RF model performed well in the training set, it was outperformed in the test set by the ANN model. The ANN model was chosen to model and forecast the GBP and NGN exchange rate during the Covid-19 pandemic. The predicted fall in the GBP to NGN exchange rate to 570 by December 2021 and 575 by September 2022 using the ANN model will have a huge effect on the economy of the country because the country depends largely on imported goods. The Government and policymakers must put in place structural measures that will avoid the looming crisis in the country. More attention should be given to the other economic factors such as oil prices and importation in order to manage the exchange rate rather than focus solely on the Covid-19 pandemic, and there should be a system to support and promote locally made goods.

Conflict of Interest: The authors declare that they have no conflict of interest

Availability of data and material: Yes (Figshare) https://figshare.com/articles/dataset/GBP to NGN/16575029

\section{References}

[1] Appiah, S. T., and Adetunde, I. A. (2011). The forecasting exchange rate between the Ghana cedi and the US dollar using time series analysis. Current research journal of economic theory, 3(2), 76-83.

[2] Babu, A. S., and Reddy. S.K. (2015). Exchange rate forecasting using ARIMA, Neural Network, and Fuzzy Neuron. Journal of Stock and FOREX Trading, 3(4), 1-5. 10.4172/2168-9458.1000155.

[3] Bartholomew, D.C., Orumie, U.C., Obite, C.P., Duru, B.I., and Akanno F.C. (2021), Modeling the Nigerian Bonny Light Crude Oil Price: The Power of Fuzzy Time Series. Open Journal of Modeling and Simulation, 9, 370-390.

[4] Box, G.E.P., and Jenkins, G.M. (1976). Time Series Analysis: Forecasting and control. Rev. ed. San Francisco: Holden-Day. doi:10.1109/34.709601.

[5] Breiman, L. (2001). Random Forest. Machine Learning, 45(1), 5-32 http://dx.doi.org/10.1023/A:1010933404324

[6] Etuk, E.H. (2014). Modeling of Daily Nigeria Naira - British Pound Exchange Rates using SARIMA methods. Current Journal of Applied Science and Technology, 4(1), 222-234. 10.9734/BJAST/2014/5535.

[7] Etuk, E.H. (1998). An Autoregressive Integrated Moving Average (ARIMA) Simulation model. A case study. African Journals Online, 10(1), 2326.

[8] Hanson, J., and Craig, R. N. (1985). Interest Rate policies in selected developing countries, 1970-1982. World Bank staff working Papers, 753.

[9] Jameela, O. Y. (2010). Exchange rate changes and output performance in Nigeria. Pakistan Journal of Social Sciences, 7(5), $380-387$.

[10]Nwokike, C.C., Offorha, B.C., Obubu, M., Ugoala, C.B., and Ukomah, H.I. (2020). Comparing SANN and SARIMA for forecasting the frequency of monthly rainfall in Umuahia. Scientific African, 10. https://doi.org/10.1016/j.sciaf.2020.e0062.

[11] Nwosu, U.I., and Obite, C.P. (2021). Modeling Ivory Coast COVID-19 cases: identification of a high-performance model for utilization. Results in Physics 20. https://doi.org/10.1016/j.rinp.2020.103763

[12] Nwosu, U.I., Obite, C.P., and Bartholomew, D.C. (2021). Modeling US Dollar and Nigerian Naira Exchange Rates During COVID-19 Pandemic Period: Identification of a High-performance Model for New Application. Journal of Mathematics and Statistics Studies, 2(1), 40-52. https://doi.org/10.32996/jmss.2021.2.1.5

[13] Obite, C.P., Bartholomew, D.C., Nwosu, U. I., Esiaba, G.E., and Kiwu, L.C. (2021). The Optimal Machine Learning Modeling of Brent Crude Oil Price. Quarterly Journal of Econometrics Research, 7(1), 31-43. https://doi.org/10.18488/journal.88.2021.71.31.43

[14] Obite, C.P., Chukwu, A., Bartholomew, D.C., Nwosu, U. I. and Esiaba, G.E. (2021). Classical and Machine Learning of Crude Oil Production in Nigeria: Identification of an Eminent Model for Application. Energy Reports, 7, 3497-3505. https://doi.org/10.1016/j.egyr.2021.06.005

[15] Obite, C.P., Olewuezi, N.P., Ugwuanyim, G.U. and Bartholomew, D.C. (2020). Multicollinearity Effect in Regression Analysis: A Feed-Forward Artificial Neural Network Approach. Asian Journal of Probability and Statistics 6(1) 22-33. https://doi.org/10.9734/AJPAS/2020/v6i130151

[16]Okon, E. J., and Ikpang, N. (2020). Modeling and Forecasting Exchange Rate values between Naira and US Dollar to assess the effect of the Covid-19 pandemic period on the Rate. Asia Journal of Probability and Statistics, 8(1), 55-65. 10.9734/ajpas/2020/v8i130200.

[17]Olden, J.D., Michael, K.J., and Russell, G.D. (2004). An accurate comparison of methods for quantifying variable importance in artificial neural networks using simulated data. Ecological Modeling, 178, 389-397. 
[18]Onasanya, O. K., and Adeniji, O. E. (2013). Forecasting Exchange between Naira and US Dollar using the time-domain model. International Journal of Development and Economic sustainability. 1(1), 45-55.

[19]Ozil, P. (2020). Covid-19 in Africa: Socio-economic impact, policy response, and opportunities. International Journal of Sociology and social policy. http://doi.org/10.1108/ijssp-05-2020-0171

[20]Udoye, R.A. (2009). Determinants of the exchange rate. M.sc dissertation (unpublished). Department of Economics, University of Nigeria Nsukka.

[21]Weihang, L., and Zhang, R. (2011). A regression model on the effective exchange rate of RMB based on Random Forest. International Conference on E-business and E-Government (ICEE). 10.1109/ICEBEG.2011.5882520.

[22]Yao, J. and Tan, C. L. (2000). A case study on using Neural Networks to perform technical Forecasting of FOREX. Neuro Computing, 34, 79-98.

[23]Zhang, G. P. (2003). Time series forecasting using a hybrid ARIMA and Neural network model. Neuro computing, 50, 159-175. 10.1016/50925312(01)00702-0. 